\title{
Belief System as Medium for Prayers: A Perspective From Radhasoami Point of View
}

\author{
Shanti Sarup Gupta \\ Himachal Pradesh Electricity Regulatory Commission, Shimla, India
}

\begin{abstract}
All impressions of acts, desires, and thoughts are preserved in the highly elastic Manakasa. They are transmitted to destination by the elasticity and constitute centres of further acts. These impressions travel life through life and are known as Samskaras and determine the circumstances, qualities, and attitudes of an individual. They form the founding belief system which firms up and matures with spiritual training, development, and experience of an individual in the small space allocated to free-will. The fountainhead of quantum spiritual force field is the Supreme Being; field is compact in purely spiritual, lesser in spiritual-material, loose in material-spiritual region, and void in nether pole. The basic flux is the attraction of spirit, mind, and the matter respectively which bind the particles together. The God-particle discovered by scientists is the physical particle of the material-spiritual region. The God-particle of spiritual-material region is subtler. The supreme God-particle of spiritual region is the subtlest. The scientists are far from it. All arrangements in creation are carried through currents. Similarly, the entire economy of this physical body is regulated by currents, known collectively as the nervous system. Networks of currents spread out in individual systems/sub-systems. Humans are wired in these networks and constitute its quanta in the quantum force field. Network conductors in the creation are so programmed as to recognize only the Dhunyatmak sounds which reverberate on their own. The sensory conductors in the human body shall take the call only when the individual spirit tunes in with the Dhunyatmak sound characteristic of that Region. When that happens, one's spirit is transported to that region. The spiritual force field is agitated by the meditation; the particles of that force field coalesce to form conducting particles which constitute the path thru the particular artery connecting the spirit entity with the presiding deity on virtual form. Belief, degree of consciousness, faith, and love for a deity are synonymous. Belief system is fundamental to human existence. One's religion is basically his/her belief system. Each individual belief system is unique. Human existence is composed of spirit, mind, and the body each having its own reservoir. Man is de-facto the microcosm while creation is macrocosm. Man represents all spheres of the creation. Devotion, love, and faith for the Lord are embedded in the microcosm or individual belief system with sustained meditation over a period of time which help in establishing communication channels with the macrocosm. Nevertheless, the devotion of a helpless human being can never be perfect and pure. It is always corrupted by the internal noise and pernicious propensities. God is conquered and he is willing to be conquered by his lovers. Lord is the sea of "grace and mercy". He accepts even the corrupt Bhaktieven when the belief systems are not firmly embedded in the nerve systems of the people who are driven to prayer meets by personal and selfish ends.
\end{abstract}

Keywords: microcosm, macrocosm, karmas, Samskaras, quantum force field, Manakasa, Dhunyatmak 


\section{Introduction}

Moksha-Karmas-Samskaras Theory of Hinduism is the theory of preservation of impressions on the Manakasa which is responsible for metempsychosis. Manakasa is the world mind or the mind sky on which all acts, thoughts, and desires are recorded as impressions which form the centres for all future actions and determine the next birth. Strictly speaking, these impressions inscribed from life to life and not the karmas per se determine the Samskaras of the new born who starts fresh journey of life. These Samskaras in turn form the foundation for the unique belief system of an individual. According to the Radhasoami belief, there is some scope for free-will also in the human entities which is their precious privilege. This is this free-will which further shapes the belief system through the life of an individual. It takes roots as one grows and develops his belief system. This belief system then adheres to and accompanies the soul in its metempsychosis. Eradication of the karmic impressions leads to Moksha (salvation).

Human body is a perfect microcosm of the macrocosm of the universe. In other words, man is an analogue of God. Correspondence between the human microcosm and the creational macrocosm takes place in four stages: through (1) individual belief system; (2) into the subtle apertures associated with the nervous system of the human body; (3) through network of gross as well as subtle currents in the macrocosm; and (4) finally with the corresponding Deity. This paper discusses the concept of belief system in this context. It highlights how offerings of prayers and services travel through the network of belief system, and nervous system to finally reach the target deity.

\section{Impressions \& Samskaras}

Spirit force is the prime force, the power of which is so great that when and wherever it manifests itself, all forces of nature, tattvas (elements) and Gunas (various qualities), etc., immediately collect there and function together in cooperation. When, however, it leaves the body, its form, colour, and vitality disappear immediately, and that body assumes an extremely frightful or fearful appearance. All the functions of that body and of its different parts stop altogether. The spirit force is the force of life that has created human body. It is simply untenable to believe that the force of life could disappear at the time of death.

Abercrombie (1849), in his treatise "Intellectual Powers", had mentioned cases of several ladies and gentlemen who recollected and repeated some foreign verses, which had at some time come within the range of their hearing. Param Guru Maharaj Sahab, the third Revered Leader of Radhasoami tradition, discourses that

the surroundings act upon the senses and the impressions produced in the latter are perceived at the time, but the matter does not terminate at that stage. All these impressions are preserved somewhere within us, even the most insignificant and feeblest of them finding a place in the internal record. The medium on which all such impressions, viz, those produced through the senses and also those which are due to subjective actions, are recorded and preserved is the ether...Akasatattva or ether, upon which the impressions received through the senses are recorded, is known as Manakasa (mind sky). This Akasa possesses an elasticity of an immensely high character, identical with the elasticity of ether found in creation. By means of this elasticity the impressions produced in Manakasa or in the ordinary ether of nature are transmitted to their destination. The destination in the case of natural disturbances is radiative, while in the case of Manakasa, although this function is not wanting, it is subjective. Mind with its four functions becomes cognizant at the time the impressions are being recorded, but with the diversion of attention to other impressions and in other directions, the consciousness of the previous impressions fades and gradually they pass away from the ordinary schedule of memory. The impressions are, however, by such disappearance, are not entirely effaced. They are scrupulously preserved in the old records of Manakasa. When these are approached, whether voluntarily or involuntarily, by complete convergence of attention towards them, they are forthwith reproduced and recollected as explained above. 
The author concludes by saying

from the cases mentioned by Abercrombie, which we have stated above, two principles are clearly deducible, viz,

(1) that an entity, by the association of complete attention with the impressions it has received, performs acts entirely in accordance with the nature of those impressions, even when the impressions are extremely feeble and even when they are not intelligible; and

(2) That these acts react upon the Manakasa, and that under favourable circumstances, viz, by complete association of attention with them, they can again constitute centres of future action. (Sabha, 2004, pp. 154-156)

Velmans (2009) avered that the human minds, bodies, and brains are embedded in a far greater universe. Individual conscious representations are perspectival. The precise manner in which entities, events, and processes are translated into experiences depends on the location in space and time of a given observer, and the exact mix of perceptual, cognitive, affective, social, cultural, and historical influences which enter into the "construction" of a given experience. In this sense, each conscious construction is private, subjective, and unique. This results from a reflexive interaction of entities, events, and processes with our perceptual and cognitive systems that, in turn, represent those entities, events, and processes. However, such conscious representations are not the thing-itself. In this vision, there is one universe (the thing-itself), with relatively differentiated parts in the form of conscious beings like ourselves, each with a unique, conscious view of the larger universe of which it is a part. In so far as we are parts of the universe that, in turn, experience the larger universe, we participate in a reflexive process whereby the universe experiences itself. Velmans (2009) suggested that the human brain is a nested hierarchy that contains brains within brains, minds within minds, and consciousness within consciousness from the earlier existences. All this is enclosed within the human brain, the individual mind, and the individual consciousness which cumulatively constitutes one's Samskaras (Velmans, 2009, pp. 266, 298-353).

Velmans' consciousness in its ultimate manifestation is the "Chaitanya" of Sant Mat or Radhasoami Tradition.

Paramguru Huzur Maharaj, the second revered leader of Radhasoami Tradition, surmises that Samskaras are nothing but the products of impressions of cumulative karmas of all kinds. Man's "Samskaras" determine the circumstances of his life, his physical and intellectual qualities, his attitudes and aspirations, his desires as well as his abilities are in a way determined by his "Samskaras" [Sabha, 1959a, p. 78, footnote 1; 1959b, p. 268).

Samskaras are impressions or conformations which control all actions, good and bad, of man on the physical as well as mental plane. Samskaras of previous lives remain piled up and produce fresh cravings and desires and these again lead to further actions and thus to new Samskaras. Samskaras are said to be both good and bad according to the good and bad effect they produce on a man's nature” (Sabha, 1959b, p. 268, footnote 1).

In Hindu philosophy, this consciousness or knowledge can be summed up as Samskaras that are inherited at birth. The Karma-Samsara-Moksha Theory is something unique and original in Hinduism. The concept of karma is now finding its way into the Western literature and Western researches also. In Indian philosophy, karma is the sum total of one's actions, good or bad, that are attached to the soul as it transmigrates, each new body (and each event experienced by that body) being determined by previous karma. Inborn cravings and deep-rooted desires in an individual result in actions called karmas. Desire is the cause of all actions which in turn result in an effect. This cause and effect is seen in all possible phenomena. 
The Bhagavad-Gita, the Holy Book of Hindus, which records the conversation between Lord Krishna and his childhood friend and companion, points out that no one with physical body viz. human beings, animals, vegetables, and minerals can escape the law because they are all evolving within this universal law. As long as any one is related to or embodied in matter, he/she remains within karmic law.

Karma is now familiar in the Western World, too. Karma is often seen as a system of cosmic justice that explains our present predicament as a reward or punishment for our good and bad actions in the past, both in this life and in previous incarnations. (Juergensmeyer, 1991, p. 206)

The majority of spiritual traditions agree that death is but a new beginning. They teach that after death we reincarnate into another human body to continue our journey of spiritual evolution. This is taught by Hinduism, Buddhism, Taoism, and Shamanic traditions as well as by mystics within other traditions, such as Jewish Cabalists, the Gnostic Christians, and the Islamic Sufis (Juergensmeyer, 1991, p. 225). It has found favour with nearly half the world's population and some Greek schools of philosophy.

In Hindu, Buddhist, and Jain philosophies, the life we are living has been lived several times over by us and all the previous lives have become part of us. Karma is a basic principle in Jainism and human moral actions form the foundation of the concept of transmigration of souls. Karma is also conceived of as an extremely subtle matter which enters the soul and veils its natural, transparent, and pure qualities. The matter pollutes the soul in various colours called lesya.

Each individual takes birth thru an actualization of the train of its old karmic impressions and is a summary of innumerable earlier existences. So do the Buddhists and the Jainisbelieve. We, however, are looking at only brief chapter in a very long story. Chain of personal desires and effects are links with endless extensions of births and deaths. In fact, such belief is shared by more than half of the world. Strictly speaking, the impressions inscribed from life through life on the hard disc of the mind sky and not the karmas per se determine the Samskaras of the new born who starts fresh journey of life. These Samskaras in turn form the basis for the unique belief system of an individual. According to the Hindu belief, this is almost tantamount to fatalism.

However, Sant Mat or Radhasoami Tradition teaches that there is some scope for the free-will also in the human entities which is their precious privilege. This is this free-will which further shapes the belief system through the life of an individual. Belief system thus becomes a function of the degree of spiritual consciousness, faith, and love for the Deity. It takes roots as one grows and develops his/her belief system. This belief system then adheres to and accompanies the soul in its metempsychosis. Eradication of the karmic impressions leads to Moksha (salvation).

\section{Belief System}

One has to have belief in something in life. Belief and faith are synonymous. There cannot be a person without a belief, be it in his/her ability, strength, courage, principles, commitments, religion, rituals, ceremonies, God, or for that matter anything. Belief system is a part and parcel of an individual without which the very existence cannot be imagined. It is ingrained in one's personality. True and firm belief is not liable to shake. It profoundly interacts with and influences one's behaviour, conduct, social relations, motivation, and culture which in turn influence the belief system. This is an ongoing process and continues throughout life after life. 
The faith is of three types; faith borne out of understanding; faith after seeing; faith on being one with the Lord. True lovers of Lord make it a part of their daily religious training and practice to keep on praying for the gift of firm faith in the lotus feet of the Lord and the living hope of Grace and Mercy from the Lord. A sample prayer offered by the followers of Radhasoami Tradition together with authoritative translation is given below:

Tere Charanonmeinpiyare hey Pita

Mujheaisadrirhvishwasho

Ki man mein mere sadaasra

Teri DayavaMeharkiaasho

(May I have firm faith in Your Lotus Feet, Dearest Father?

And rely always on Thy Mercy and Grace.)

(Sabha, 2006, pp. 126-127)

It is very difficult to keep the flame of one's faith (without seeing and without being one with the Lord) burning midst long stormy weather. That is where the danger lies. Bravest, thus are those who maintain their belief even without any experiences. That is why Lord Jesus says in the Bible, "My Father and I are one. Blessed are they who have seen the Father and believe in Him, but more blessed are they who have not seen the Father and yet believe in Him”.

Belief matures and ripens with understanding, experiences, and intuitive knowledge, supra-cortical consciousness, and ultimately the cosmic consciousness. In other words, proof lies in eating the pudding and not before one eats it.

Faith and belief are the most difficult things particularly when these postulates are not backed up by any tangible objective proof acceptable to a man of science. Here comes the greatest handicap. One is asked to pin his/her faith in the subjective knowledge acquired by others with the hope and promise that if he/she also tries, he/she may also acquire similar subjective or intuitive experiences. It requires the heart of a lion and the obstinacy of a mule to harbour such faith. Someone might say it would be blind faith. It may be so for some but once one has understood the theory and is convinced about its authenticity at least in terms of scientific scrutiny, it no longer remains blind. It is Ilam-ul-yakin-faith borne out of understanding.

Consciousness, faith and love are functions of the belief system. Simply stated $b=f(c, f, l)$ where $b$ is the belief, $c$ is the consciousness, $f$ is the faith, and $l$ is the love. Belief system is a complex phenomenon and while consciousness is one of the functions of the belief system, another equally or even more important factor namely "love" is, indeed, the most important function of the belief system. Without consciousness, faith, and love, belief system is very fragile and liable to shake-ups.

In this context, one is reminded of the famous words of William Wordsworth:

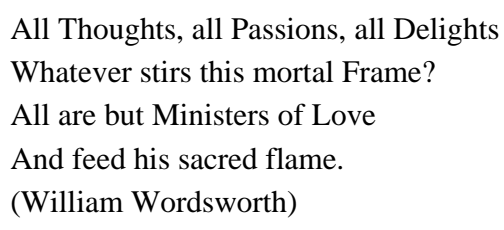

The poet sums up everything that happens to the humans as various manifestations of love. Most Revered Prof. Satsangi, the present Leader of Radhasoami Tradition (Dayalbagh Group), discourses that according to researchers in the field of spiritual consciousness, if we consider reasoning (derived from knowledge and intelligence) as one unit, the level of love in terms of consciousness is much higher than that of the reasoning; 
i.e., if you multiply 10 by itself hundred times the number you get would represent the level of love in comparison to the level of knowledge and learning (Dayalbagh Herald, 2009). Paramguru Huzur Sahabji Maharaj, the fifth Revered Leader of Radhasoami tradition (Dayalbagh) in Discourse 94 of the Bachans of Paramguru Maharaj Sahab, Paramguru Sarkar Sahab and Paramguru Sahabji Maharaj, declares that just as the light is the amalgam of seven colours, similarly love is the amalgamation of Sat, Chit Anandand Prakash, i.e., truth, consciousness, bliss, and refulgence.

Velmans (2009) argued that consciousness sometimes alludes to knowledge in the sense that if one is conscious of something, one also has knowledge of it. In that manner of speaking, level of love in terms of consciousness (call it knowledge) is $10^{100}$ times the level of knowledge and reasoning.

Superstitions, however, do not fall in the category of beliefs. They are the other name for ignorance but are nevertheless the result of one's karmas and hence of the Samskaras and suggest journey thru dark domains of the physical universe. Blind faith or belief is another stage quiet different from superstition. It is the belief or the faith without proper understanding or scientific explanation of the phenomenon. Some say that blind faith is better than the faith built on logic. Anecdotes are advanced in support of the statement that the faith can move the mountains and lack of it can deny the very existence thereof. Nevertheless, the faith or the belief is the very sine qua non of one's existence as stated above.

Religion is basically a belief system rather belief system is the bedrock and at the core of a religious tradition. Without belief, religion is a hollow proposition. Science without religion is lame, but religion without belief is hollow. Theoretical belief arising out of intellectual understanding cannot be firm and impeccable. It is liable to shake at any up and down in life. It is also severally subjected to the pernicious influence of evil concealed in the individual ego. The belief or the faith in anything, even in God can never be impeccable and absolute without experience. It is always wavering, shaky, and liable to slip. Those who profess their faith or belief to be unshakable or firm like rock are only deluding themselves. Wrung through some test, they are most likely to fail. The reason is not far to seek. The human mind is such a complex labyrinth of innumerable impressions of innumerable past lives that any firm belief cannot entrench itself into a nerve system and is most likely to be rejected as alien by the nervous system unless it has been cultivated as part of it in the previous lives as well. A slight hit to it by whatever causes, impressions, or delusions can shake it to irretrievable levels.

Each belief system is unique. When individuals congregate at one place for any religious activity, this constitutes congregation of numerous and unique belief systems at varying degrees of maturity, firmness, and entrenchment in the respective nervous systems. Their nervous systems are not entirely devoid of the evil and the filth and thus are choked to varying degrees. It cannot be a coherent and coalescing congregation and remains such in name only. The religious activity of such a fragmented, heterogeneous, and cryptic congregation cannot bear fruit unless it is in unison and in complete resonance with its constituents. More often than not, they remain individual, unique and isolated, as if not in actual congregation and instead performing that activity as an individual in noise. The spiritual glue that binds the constituents of the congregation is missing. That individual system thus gets corrupted by the noise of that congregation.

\section{Microcosm \& Macrocosm}

Human existence, as we all know, is composed of three factors, namely, the spirit, the mind, and the physical frame each having its own independent and distinct reservoir. The ordinary functions of the physical frame, including the entire nervous system, consist of the life-giving, life-sustaining, and the responsive powers. 
This proposition broadly includes all the ordinary physical and subjective conditions of human life. Underlying the planes of ordinary functions of the human frame, there are subtler planes within the nervous system. The innermost part of each nerve centre is associated with the subtle plane peculiar to it (Sabha, 1959a, p. 229).

The saying that God created man after his own image is confirmed by the fact of man's superiority over all other creatures in this world. The outlines of the human form have been adopted with more or less precision in the structure of the whole animal kingdom. This very image can be traced backwards and upwards in a more and more perfect order till we reach the first form, the most perfect, and originally assumed by the spirit current, when commencing the work of creation namely the Supreme Being ${ }^{1}$.

In that manner of speaking, human body is a perfect microcosm of the macrocosm of the Universe. In other words, man is an analogue of God (Sabha, 2010, pp. 9-10).

Man, from his position in the universe and from the amount of spirituality he possesses, is thus endowed with a cosmos of his own which is so constructed as to represent all the spheres of the entire creation from the highest spiritual source down to the creationless nether pole, and which possesses such apertures and potentialities as would enable the human entity to reach the highest mansion (Sabha, 2004, p. 130).

In the man, all the regions from that of the Supreme Being at the top, down to Brahmanda in the middle and further down to Pind at the bottom are represented. The human body is an epitome of the entire universe in as much as all the elements employed in the evolution of creation and all the stages passed through by it since its beginning are represented in it on a miniature scale. In simple words, the genes of different regions as above are implanted in the human body in the 18 apertures called the "Chakras", "Kamals", and "Padams". When looked that way, the human body shall appear to be an epitome of the greatest blessing from the creator himself.

\section{Quantum Force Fields \& Network of Currents}

The fundamental axiom of macrocosmic/microcosmic spiritual consciousness as enunciated by Most Revered Prof. Satsangi, is that the origin of the macrocosm is an infinite spiritual energy source or reservoir known as the Supreme Creator or Being or Super Positive pole accompanied by the omni-quantum spiritual force field of consciousness ranging from the Super positive pole of full spirituality to the Nether or Negative Pole of depleted spirituality; and each constituent fundamental particle of this Omni-quantum spiritual force field, known as the spirit-force of consciousness (monopole), is the one which possesses prime energy and that all other forces (mental or physical) of creation or nature have been evolved by the association of this spirit-force with media (mental or physical) of different kinds. The concept of "spirit-force" is no more intrinsically mysterious than "mass". This gives rise to the quantum mind-force field which spans the Region of the Universal Mind and the Physical Universe, on the one hand, while the quantum physical force fields-electromagnetic, weak nuclear, strong nuclear, and gravitational span the third grand division, viz., the Physical Universe (Pind) of the Macrocosm (Sabha, 2010, Appendix, p. vi).

The concept of omnipresent quantum spiritual, mind, or the physical force fields is very similar to that of magnetic field. A magnetic field consists of imaginary lines of flux or currents coming from moving or spinning electrically charged particles. What a magnetic field actually consists of is somewhat of a mystery, but we do know it is a special property of space.

\footnotetext{
1 Sabha, Radhasoami Mat Prakash, p. 37.
} 
All arrangements in this creation are being carried out through currents, whether the latter be visible or, not. Just as external creation is maintained by currents like the ones in a magnetic field, in the same manner, the entire economy of this physical body is maintained by currents, known collectively as the nervous system. These currents are subtle in the subtle regions and gross in the regions of gross matter (Sabha, 1959a, pp. 299, 300).

There are numerous currents at work in carrying out the arrangements of the creation. The physical creation, that we are able to see with our eyes or with the most powerful telescopes, represents but a tiny fraction of a percent of the whole. Far greater and subtle expanses and regions exist in innumerable Brahmandas and much larger and subtler expanses and regions exist unperceived and unrealized beyond Brahmandas in Purest Spiritual Region (Sabha, 2004).

The networks of currents have numerous locks and interlocks inbuilt in their course up and down which prevent one from spilling into another as in the case of physical worlds which are kept at safe distances from one another and keep the respective regions within the permissible distances from one another.

The current with which a spirit entity comes down to this earth and is so sustained in life is the current of consciousness. Similarly, there are currents of love, of Sabda (sound which resonates on its own), consciousness, virtues, ethics, character, passions of anger, lust, greed attachments, ego, etc., representing every conceivable human emotion and passion. There are, indeed, 1,000 combinations and permutations of principle currents of Purush, Prakriti, and Kal in combination with five tattvas ${ }^{2}$, three gunas ${ }^{3}$, two genders, compounded into 25 prakritis, representing every human tendency to associate with matter and the mind (Sabha, 2004, pp. 104-107).

These currents and networks spread out in all directions in individual system and sub-systems like the ones in a magnetic field; in the same manner, the entire economy of this physical body is maintained by currents, known collectively as the nervous system.

These currents are subtle in the subtle regions and gross in the regions of gross matter. There cannot be any mix-up of one sub-system with another sub-system and one system with another system. They remain absolutely independent and yet connected with the overall creational system thru principle connecting currents. Nevertheless, they have individual quantum force field, spiritual in the purely spiritual regions, spiritual-material in Brahmanda, and material-spiritual in Pind where they exercise omnipresence and omnipotence in the respective spheres and regions below them.

The current with which a spirit entity comes down to this earth and is so sustained in life is the current of consciousness or Chaitanya. All the functions of this creation are being carried on by Chaitanya. Whatever exists merely represents a variation in the degree of spirituality, and that the evolution of creation has not introduced anything beyond a series of innumerable grades of spirituality which did not exist previously. The innumerable varieties in shape, colour, refulgence, energy, intelligence, bliss, etc. are all due to the different experiences produced by different degrees of spirituality (Sabha, 2004, p. 146).

\footnotetext{
2 The five tattvas or elements represent the five conditions of matter, viz, solid, liquid, gaseous, incandescent, and ethereal (Sabha, 1959a, p. 154).

3 The three gunas, viz, Sattva, Rajas, and Tamas as qualities or principles pertaining to creation mean "quality of stability or existence”, “quality of energy or action”, and “quality of inertia or resistance to action” respectively (Prem Patra Part I, p. 69). The three gunas, viz, Sattva, Rajas, and Tamas in reference to man, represent the qualities of: (i) equilibrium or goodness-mood of righteousness; (ii) energy and activity or passion-mood; and (iii) inertia and resistance to action or darkness-mood (Sabha, 1959a, p. 55).
} 
The fountainhead of omni-quantum spiritual force field is the Supreme Being Himself; the field is totally compact and packed up in the purely spiritual region, lesser in the region of universal mind, mixed with constituent fundamental particles of quantum mind force field of the Universal Mind as it is, very loose and least dense in the physical universes (Pind) mixed now with constituent fundamental particles of quantum mind force of the universal mind as well as of the quantum physical force field of the Physical Universe. Fundamental constituent particles of omni-quantum spiritual and quantum mind force fields are almost absent at the nether pole. There are only constituent fundamental particles of quantum physical force field here.

Each subtlest particle in the purely spiritual region resonates clear and loud in its respective sub-division, the highest lending force to those below it, each adding its own resonance to the sub-divisions below until it reaches the lowest sub-division in the region. In other words, the resonance of the lowest sub-division in the purely spiritual region enshrines within it the six resonances-five of those above it and one of its own, the highest in the core and others one above the other. Its own resonance is in the outer layer. When the field extends to the region of Universal Mind, it is engulfed by the subtler and subtle particles of the mind force field adding resonances of the sub-divisions of the region as it descends below. When both the omni-quantum spiritual and quantum mind force fields extend further down to the physical universe, the quantum physical force field joins the two namely the omni-quantum spiritual and quantum mind force fields and add the resonances of respective sub-divisions of the physical or material region. In other words, here, the particles of the physical force field are predominant, those of mind force field are lesser, and those of the spiritual force field are very sparse. They are then distributed unevenly in every animate and inanimate object resulting in different degrees of consciousness. At the nether pole proper, subtlest particles of the spiritual force field are almost absent, subtler and subtle particles of mind force field are sparse and very loose while the particles of physical force field are compacted heavily. The distant echoes of resonances crowded with noises of the physical region may, however, reach the nether pole. This is the region of hell.

In all three regions namely Purely Spiritual, Universal Mind, and the Physical Universes, the basic flux is that of attraction or love of the spirit, of the mind and of the matter respectively which holds the respective constituent particles together. The God-particle or the Higgs Boson claimed to have been discovered by the scientists at CERN is, in fact, the physical particle of the physical universes with which we are familiar. The God-particle of the region of Universal Mind namely the "Mind" is far more subtle and not susceptible of either measurement or discovery by any known or yet to be invented instruments. The omni-quantum Supreme God-particle of purely spiritual region or the region of purest spirit namely the "spirit" is the subtlest and absolutely undiscoverable and unexperiential except thru meditation or Surat Sabda Yoga. The scientists are nowhere near the subtler God-particle of the region of Universal Mind, to speak nothing of the Supreme or Original God-particle of the purely spiritual region which constitutes the basic building block of the entire creation.

The creation came into existence with the help of these currents, is maintained, sustained, expanded, and destroyed by these currents. Just as the omni-quantum spiritual force field extends from the super positive pole of spirituality down to the nether pole of depleted spirituality, quantum mind force field extends from the top of the region of universal mind to the nether pole and the quantum physical force field extends from the top of the region of Pind or the material-spiritual region down to the nether pole. The omni-quantum spiritual force field encompasses all other force fields while the quantum mind force field encompasses the physical force field within it. Every spirit entity in pure spiritual region, in the region of Universal Mind (Brahmanda), or in the 
Physical Universes (Pind) comes under the direct influence of the respective force field together with the force field that encompasses it. Each spirit entity in all four classes ${ }^{4}$, namely placenta, egg, moisture, and soil in physical universes (Pind) is wired in the network of currents, indeed up to one thousand of them which are then connected with the principle currents upwards and downwards. The downward currents are responsible for metempsychosis in Chaurasi while the upward currents can lift it beyond Pind into the region of universal mind Brahmanda or even to the purest spiritual region and ultimately to ones original home or the home of the Supreme Being (Sabha, 2004, pp. 104-105).

Just as the economy of the human frame is regulated by means of its nervous system, similarly the economy of creation is regulated by means of currents. Both systems namely the human nervous system and the creational current system are interconnected thru complex and subtle sensory connectors which remain inactive most of the time.

The innermost part of each nerve centre in the human body is associated with the subtle plane peculiar and corresponding to it. When these subtle planes are acted upon through nervous centres by means of meditation, communion with the macrocosmic spheres corresponding with them is established, higher powers of these spheres are imbibed and higher consciousness with greater degree of intelligence and wisdom manifests (Sabha, 2004, p. 32).

We, human beings, are wired in this network of currents and constitute its quanta in the quantum force field which is encompassed by the quantum physical force field as the top layer, quantum mind force field as the next layer and finally the omni-quantum spiritual force field as the innermost layer.

The entire omni-quantum spiritual force field besides being a grand firework or network of spiritual currents is packed with flux of love and love in which these currents are dancing. This is dance of currents in cosmic flux of love. If one wants to participate in this great dance, all that one ought to do is to supplant this ambience of love with his/her love, faith, belief, and true and pure devotion; and he/she can join this great carnival. However, since the flow of spirituality has been downwards from life thru life, to turn it northwards is tantamount to swimming against the tide which is impossible without love. Love acts as spiritual lubricant or catalytic agent and allows the smooth flow of intonations to their destination from the individual belief system thru the network of currents. The true lovers of the Lord therefore, always pray for the blessings of love and faith in the Lotus Feet of the Lord. Supreme Being is an infinite ocean of all absorbing rapture and, of supreme intelligence from which nothing remains concealed, of supreme energy or spirit which supplies force and vitality to everything and of supreme light, whose lustre is indescribable. In this all-glorious condition, eternal and infinite, unaffected by anything He exists. Lord is the Infinite Ocean of Love and Love and therefore his true lovers beg for Him from Him (Sabha, 1960, pp. 54, 55, 57).

\section{Dynamics of Prayers and Services}

The correspondence and communication of the microcosm with the macrocosm takes place by means of apertures in the microcosm. The main factor of the communication is, however, the spirit or the sensory current permeating these apertures. The innermost quarters within these apertures, by means of which the microcosm is associated with Brahmanda and the purely spiritual regions are of supreme importance. There are subtler planes

\footnotetext{
4 Jivas are said to be of four classes according to the manner in which they were born. These are called jeraj: that which comes out of placenta, andaj: that comes out of an egg, svedaj: that which comes out of water and perspiration and udbhij: that which comes out of earth (Sabha, 1959a, p. 299).
} 
within the nervous system, and the innermost part of each nervous centre is associated with the subtle plane peculiar to it. When these subtle planes are acted upon through nervous centres, communication with the macrocosmic spheres corresponding with them is established, and the powers of the presiding deities of these spheres are imbibed. The brain from which all the lower nervous centres have been created is similarly associated with very subtle planes. They do not belong to the part of creation within our vision, but to the higher regions of creation, viz, to those of the Universal Mind and to those of the pure spirit, the true Supreme Being. By developing the powers of these planes in the brain, communication can be established with Brahma and the true Supreme Being (Sabha, 2004, pp. 28, 32, 33).

Most Revered Prof. Satsangi Sahab in the Macrocosm-Microcosm Consciousness Interaction Postulate enunciated by him surmises that the man happens to be a perfect microcosm of the macrocosm in the sense that man possesses not only six ganglia (or "Chakras") for interaction with the macrocosm by making communion with the corresponding six sub-divisions of the macrocosmic division of the physical/material region but also six nerve-centres (or "Kamals") in the grey matter of the brain for accessing the corresponding six sub-divisions of the macrocosmic division or region of the Universal Mind as well as six other apertures (or "Padams") in the white matter of the brain for communicating with the corresponding six sub-divisions of Universal Spirit or purely spiritual region (Sabha, 2010, Appendix, p. vi).

Until the belief system becomes synchronous and coterminous with the nervous system and the nervous system itself is cleaned of the gross and subtle impurities, nothing can flow from the belief system into such clogged nervous system and into the corresponding currents leading to the destination. In simple words, the belief system and the nervous system have to become a subtly integral whole. Even after the belief system is entrenched and integrated into the nervous system, lack of love and the wistfulness for the deity, which is the necessary glue for integrating the two, would act as great obstruction and not permit the smooth flow thru its channels. On the contrary, the spaces or the gaps left between the two shall be flooded with the pernicious downward currents thus opposing the flow. Meditation with love and yearning facilitates embedding the synchronism between the belief and the nervous systems resulting gradually into permanent alteration of nervous system thru which the prayers flow upwards naturally and normally towards their region of destination which is distinct and far. In short, belief system, nervous system, love, faith, and biraha (pangs of separation from the beloved) have to become an integral whole before the services to the Lord can reach him.

When the people with similar belief systems gather for community service or prayers, there must be some medium-physical, subtle, subtler, or subtlest thru which these can travel to their destination. The services and prayers ought to travel on these network conductors to the destinations to which they are addressed. Suppose, they are the followers of Lord Krishna and their prayers are meant for Lord Krishna, they are addressed to him. These prayers and services should as matter of rule travel to the Region of Lord Krishna. However, since they are addressed to the name and image of Lord Krishna of the yore who belonged to the physical world and is no longer present and his spirituality is no longer kinetic on this plane, the network conductors are unable to recognize the address and thus prayers and the services are lost and dissipated in the air instead of travelling towards Lord Krishna's Abode which is distinct and far away at the top of the region of Universal Mind.

The reason for lack of recognition is that the sensory conductors are agitated only by the feelings, emotions, the essence, and the harmony of the invocations. They suffer violence by the burning love, biraha, and the living hope of the lovers of the Kingdom of Heavens. They have been designed and programmed by the Supreme Creator to recognize and accept only the characteristic mystic Dhunyatmak sounds of the various 
regions and sub-divisions which reverberate on their own and with which they identify themselves. Dhunyatmak or Dvanyatmaka mystic names are resounding in the inner core of every animate and inanimate object in this creation since the very commencement of creation and can be heard by meditation. These sounds are resonating within everything_-gods, human beings, demons, and all other Jivas of the four classes ${ }^{5}$, i.e., animals, birds, insects, worms, plants, etc. in the innermost recesses and is somewhat akin to the Cosmic Background Microwave Radiation emitted at the time of the Big Bang (marking the beginning of creation of physical universe) which is being detected even to this day by devices, such as Cosmic Background Explorer (COBE) Satellite as the Microwave Relic of the Big Bang to study the state of the physical universe soon after its birth (Sabha, 2010, Appendix, p. vii).

Lord Krishna lived in history in human form on this earth and when he departed from this physical world, his human body together with his physical voice mingled with their respective elements of this earth. His form disappeared from this plane and his spirit returned to his original Abode in Sunn and merged in the form characteristic of the presiding Deity of that Region. His characteristic mystic Dhunyatmak sound is Ra...r...a...a...n...g, accompanied by the musical notes of the instruments of Kingri and Sarangi and not the name "Krishna". Any communication addressed to him as Lord Krishna shall not reach him for want of correct address. Nevertheless, communications addressed to Ra...r...a...a...n...g may reach him provided they are recognized as such by the respective network conductors.

The respective sensory conductor shall recognize, accept, and resonate only if and when the individual spirit unites with that mystic Dhunyatmak sound which is characteristic of that Region to which Lord Krishna belonged. The union of spirit with the current of Sabda of Sunn requires a very high degree of purity of mind more or less of the same standard and level as of that region. Otherwise, the current of Sabda shall reject, spurn, and throw away the spirit current and refuse to unite with the dirty or unclean spirit. In other words, the individual spirit shall have to perform the practice of Surat Sabda Yoga taught by Radhasoami tradition that is yogic practice of uniting the Atman or Surat with the sound current which accompanies all emanations of spirit current for trying to unite his spirit with the sound of that region and tune with the characteristic Dhunyatmak sound of the region reverberating all the times like tuning fork. When that happens, one's spirit is transported to that region. That is the final and the ultimate stage of being one with the presiding deity of the region of destination. Until such time, even while one is performing the meditation, his prayers do reach the presiding deity by virtue of the quantum spiritual force field extending from the latter down to the spirit entity. The spiritual force field is agitated by the power of meditation; the particles of that force field coalesce and condense to form conducting particles which then form and constitute the path thru the particular artery connecting the spirit entity with the presiding deity on virtual gaun form; the latter immediately becomes cognizant of the prayer or service and the prayers thus reach the destination. That is the dynamics of prayers.

The condition, however, is quite different when the Adept is present in human form. Adepts have access to all the subtle planes of the various spheres they have traversed and gained access to. They accordingly become cognizant of the contemplation of their forms, as soon as this devotional practice is performed, and accord necessary help to the devotee. Their spirituality is kinetic on higher planes and they extend the needed spiritual assistance to the spirit entity in communicating with the presiding deity (Sabha, 2004, pp. 43, 63). When the

\footnotetext{
5 Jivas are said to be of four classes according to the manner in which they were born. These are called jeraj: that which comes out of placenta, andaj: that comes out of an egg, svedaj: that which comes out of water and perspiration and udbhij: that which comes out of earth (Sabha, 1959a, p. 299; 2004).
} 
holy service and the prayer meetings are presided over by the Adept himself, he takes notice of such service and the prayers and since he is always in communion with the presiding deity, they reach their destination instantly regardless of whether they are offered in sincerity or are corrupted. In other words, the pathos, yearning, wistfulness, in short, the very essence underlying the prayers touch and move the Adept and the kingdom of heaven suffers violence from the burning love and the living hope of the people joining in community prayers. God is conquered and he is willing to be conquered by his lovers. This is beautifully described in the following poem of Dante:

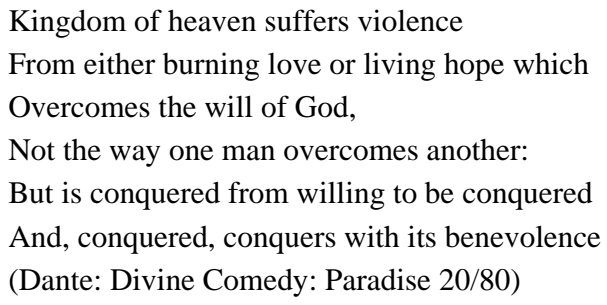

The poet's golden words are the true message of the love, grace, and mercy of the Supreme Being. He is helpless before the loving devotee. He is subordinate to the love and hope of his true devotees.

Going back to the community service and the prayers, when so many people offer the service and the prayers, numerous belief systems at various levels of consciousness are at work, taking part in such service or the prayer meeting. However, since the intra- and inter- belief systems are not in unison, invaded by the thoughts of mundane affairs as they mostly are, and discordant, disharmonious, and superficial inter-se, the prayers shall not reach their address. They shall instead be dissipated and wasted in the noise of that congregation. In order that they reach their address, it is essential that the belief systems participate and are shared by most from the inner core of their sincerity in complete concordance and harmony both intra and inter-se. Coordination and synchronization of intra and inter-se belief systems is the sine qua non for conveyance and transportation of prayers,

However, such is not generally the case. The belief systems are corrupted by not only the external noise of the congregation but also the inner noise of mind's vicious propensities caused as a result of the Samskaras. Nevertheless, the Lord being only the "Ocean of Mercy", he accepts even the corrupt Bhakti of the people even when they are driven to the prayer meets by their personal and selfish ends.

\section{References}

Abercrombie, J. (1849). Intellectual powers. New York: J \& J Harper. Juergensmeyer, M. (1991). Radhasoami reality: The logic of a modern faith. Princeton, NJ: Princeton University Press, Sabha, R. S. (2010). Exposition on truth, ultimate reality and Supreme Being.

Sabha, R. S. (2004). Discourses on Radhasoami Faith.

Sabha, R. S. (2006). Writings and Speeches of Param Guru Huzur Sahabji Maharaj.

Sabha, R. S. (1959a). Prem Patra Part-II.

Sabha, R. S. (1959b). Prem Patra Part-III.

Sabha, R. S. (1960). Prem Patra Part-IV.

Velmans, M. (2009). Understanding consciousness (2nd ed.). New York: Routledge/Psychology Press. 